\title{
Inflation, Growth, and Impatience in a Generalized Cash-in-Advance Economy
}

\author{
Kenji Miyazaki \\ Faculty of Economics, Hosei University \\ 4342 Aihara, Machida, Tokyo 194-0298, Japan \\ Tel: 81-42-783-2591Ｅ-mail: miya_ken@hosei.ac.jp
}

Received: March 29, $2012 \quad$ Accepted: April 19, $2012 \quad$ Published: July 15, 2012

doi:10.5430/ijfr.v3n3p2

URL: http://dx.doi.org/10.5430/ijfr.v3n3p2

The author gratefully acknowledges the financial assistance of Grants-in-Aid No. 21530277 and No. 22330089 from the Ministry of Education and Science, Government of Japan.

\begin{abstract}
In this note, we consider a cash-in-advance (CIA) economy in which the CIA constraint applies to not only consumption but also to all or part of investment and where the discounting rate is a function of consumption. We use this economy to investigate the effects of monetary growth on capital, money, consumption, and welfare. We find that as long as the condition assuring the uniqueness of the steady state holds, the effect of monetary growth on all of these variables is negative, though mitigated by the positive slope of the discounting function. Using this result, we establish a qualitative equivalence between the money-in-the-utility, transaction-cost, and CIA models.
\end{abstract}

Keywords: Endogenous time preference, Superneutrality, Qualitative equivalence, Cash-in-advance

\section{Introduction}

As Wang and Yip (1992) and Chen et al. (2008) have stated, the relationship between inflation and the capital stock is a central issue in monetary macroeconomic theory. Modern macroeconomics includes many approaches in terms of introducing money, with standard approaches being the money-in-the-utility (MIU), cash-in-advance (CIA), and transaction-cost (TC) approaches. In these, money is demanded either because it makes consumers happy (MIU), because they cannot buy goods without money (CIA), or because more money saves transaction costs, including time (TC). Predicting the effect of anticipated inflation on capital accumulation then generally depends on the adoption of a particular approach.

However, Feenstra (1986) succeeded in establishing a functional equivalence between the three approaches, whereby the CIA constraint on consumption only (Lucas, 1980) is a special case of a utility function in the MIU approach (Note 1) or of a transaction-cost function in the TC approach (Note 2). Feenstra (1986) also demonstrated the duality between the MIU and TC approaches, but for this purpose required a monetary model without capital and labor decisions and including a redefinition of the choice variables. The utility function used is also too specific for conventional economic analysis. With such a specification, Feenstra (1986) showed that money is superneutral in that monetary expansion does not affect any real variable other than real balance holdings.

Later, Wang and Yip (1992) established a qualitative equivalence in that they discovered the conditions in which all three approaches predict the same comparative statics results in sign by considering a monetary model with endogenous capital and labor decisions. Especially in the CIA approach, Wang and Yip (1992) considered generalized CIA constraints (Stockman, 1980) in which the constraint applies not only to consumption but also to all or part of investment. They found that when the consumption effect weakly dominates the real balance effect of money growth and some conditions are satisfied (Note 3), higher monetary growth lowers steady-state capital, labor, real balances, consumption, and welfare.

Chen et al. (2008) also shed new light on the qualitative equivalence between the MIU and TC approaches using endogenous time preferences. They showed that even when the labor supply is inelastic, a long-run negative (resp. positive) relationship between inflation and capital arises when the degree of impatience is decreasing (resp. increasing) in money in the MIU approach and in consumption in the TC approach. However, unlike Wang and 
Yip (1992), Chen et al. (2008) did not consider the CIA approach. Therefore, to complete the work begun by Wang and Yip (1992) and later Chen et al. (2008) on the qualitative equivalence of the three monetary approaches found in the literature, this note examines the effect of monetary growth on capital using the CIA model with endogenous time preferences.

This note is not the first to employ the CIA model with endogenous time preferences. For instance, Hayakawa (1995) investigated the relationship between inflation and capital when consumption and money are perfect complements in the MIU approach (Note 4) and found that money is 'strong superneutral' (Note 5), independent of the nature of time preference, using a functional specification essentially the same as that in the model with the CIA constraint only on consumption (Note 6). Nevertheless, Hayakawa (1995) did not examine the case of generalized CIA constraints. As Stockman (1985) has shown, when the CIA constraint applies to both consumption and investment, higher growth rates of money supply lower capital stock in the presence of constant time preferences. Whether this property holds with endogenous time preferences thus remains an interesting research question.

In the following analysis, we employ a CIA economy in which not only is consumption constrained but so also is part or all of investment, and the discounting rate is a function of consumption. We use this economy to examine the effect of a monetary expansion on capital, money, consumption, and welfare, and demonstrate that as long as the condition assuring the uniqueness of the steady state holds, the effect on all of these variables is negative. Importantly, we find that the sign of the effect is independent of whether the discounting rate is increasing in consumption, unlike the earlier results for the MIU and TC models in Chen et al. (2008).

In addition, by including comparative statics results similar to those in Chen et al. (2008), we establish a qualitative equivalence between the three approaches. In general, we find that higher inflation lowers steady-state capital, money, consumption, and welfare when the degree of impatience is decreasing in money in the MIU approach and in consumption in the TC approach, and when money is required not only for consumption purchases but also for part or all of investment in the CIA approach.

\section{Model and Results}

In this section, we describe our model economy, provide the monetary equilibrium and the steady state, discuss the uniqueness of the steady state, and conduct the comparative statics.

Consider a monetary economy in which $c_{t}, m_{t}$, and $k_{t}$ denote consumption, real money balances, and capital at period $t$, respectively. Technology is characterized by an increasing concave function $f\left(k_{t}\right)$ where $f(0)=0$. Representative agents are infinitely long-lived with perfect foresight and complete access to the capital market. Their preference is characterized by a felicity function $w\left(\rho_{\mathrm{n}}\right)$ and a discounting function $\rho\left(\rho_{\mathrm{n}}\right)$. We assume $u$ is increasing and strictly concave and $\rho$ is positive and concave. The homogeneous economic agents in this model face two constraints. The first is the budget constraint:

$$
k_{i}+m_{i}^{2}=f\left(n_{i}\right)+v_{i}-\rho_{i}=\sigma_{i} m_{i}
$$

where $v_{t}$ is the lump-sum transfer and $\pi_{t}$ is the rate of inflation (Note 7). The second constraint faced is the budget constraint (Note 8):

$$
q_{\mathrm{i}}+\mathrm{T} \mathrm{ki} \mathrm{m} \mathrm{m}_{\mathrm{t}}
$$

for $0 \leq \mathbb{T} \leq 1$. The cash-in-advance constraint with $\mathbb{I}=0$ applies only to the purchase of consumption, whereas the constraint with $\mathbb{I}=1$ indicates that money is also needed for investment. The former and the latter are continuous versions of Lucas (1980) and Stockman (1981), respectively. The parameter I represents the degree of credit tightness. Agents initially have capital stock $k_{0} \geqslant 0$ and money stock $M_{0} \geqslant 0$ (Note 9). They also have the following lifetime utility:

$$
\int_{0}^{1 \pi} w(a) \operatorname{mos}\left(-\Delta_{0}\right) b t
$$

where $\Delta_{t}$, determined by $\Delta_{t}=\beta\left(\sigma_{t}\right)$, represents the cumulative discounting rate. The discounting rate $\rho$ represents the degree of impatience and is a function of consumption (Note 10). When $\beta_{i} \leqslant($ resp. $A<\mathrm{J}$ ), the agents become more (resp. less) impatient as they consume more. When $\beta_{\boldsymbol{c}} \boldsymbol{\nabla} \mathbf{0}$, the degree of impatience is constant.

The representative agent chooses $\varepsilon_{*}$ and $\xi_{*}$ to maximize (3) subject to the budget and cash-in-advance constraints in (1) and (2), respectively, the initial conditions $k_{0} \geqslant 0$ and $N_{0} \geqslant 0$, and the transversality conditions. We discuss the necessary and sufficient conditions for optimization in the appendix.

The government in this model behaves in a (monetary theoretically) conventional way by printing money at a constant 
rate $\mu$ and running a balanced budget by transferring seigniorage revenues to consumers in a lump-sum fashion: $v_{t}=k w_{t}$. At equilibrium, the money and the goods markets clear:

$$
\begin{aligned}
& n_{t_{\mathrm{t}}}=\left(\omega-\pi_{\mathrm{t}}\right) m_{\mathrm{t}} \\
& k_{\mathrm{t}}=f\left(N_{\mathrm{t}}\right)-\sigma_{\mathrm{t}}
\end{aligned}
$$

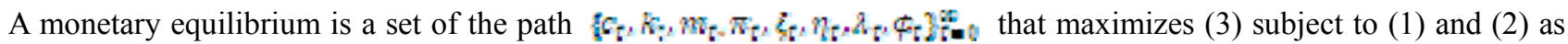
well as the initial conditions, and where the government behavior condition and the market equilibrium conditions hold. Note that $\xi_{\mathrm{z}}, \eta_{\mathrm{t}}$, and $\lambda_{\mathrm{z}}$ are the shadow prices of money, capital, and the CIA constraints, respectively, and $\phi_{\mathrm{t}}$ represents the indirect lifetime utility or welfare from period $t$. We define these variables in the appendix.

At the steady state, $k=n=k=\xi=\hbar=h=\phi=0$. The steady-state conditions (denoted by asterisks) are $\pi^{*}=\mu$, $\nabla^{4}=m^{n}=f\left(k^{4}\right)$ :

$$
\begin{aligned}
& u_{c}\left(c^{\prime}\right)-p_{c}\left(\theta^{\prime}\right) \phi^{\prime}=\xi^{\prime}+A^{\prime} \\
& \left.\eta^{\prime}\right] G^{7}=1+[M] \xi^{\prime}
\end{aligned}
$$

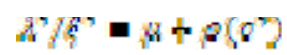

$$
\begin{aligned}
& f\left(k^{n}\right)=\rho\left(c^{n}\right) m^{\prime \prime} \xi^{\prime} \\
& \phi^{\prime \prime}=u\left(c^{\circ}\right) / \rho\left(c^{\circ}\right) \text {. }
\end{aligned}
$$

Combining $c^{s}=f\left(k^{*}\right),(7),(8)$, and (9) leads to:

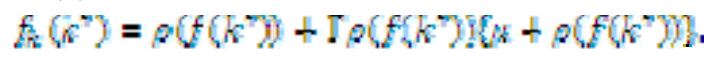

It is evident that there exists a unique $k \geqslant 0$ when $\mu+\rho(f(k)) \geqslant 0$ (Note 11) for all $k \geqslant 0$ :

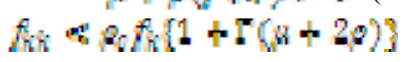

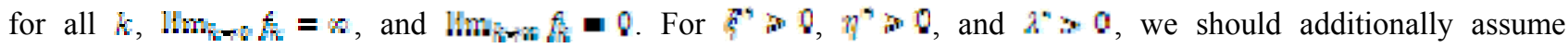
$w_{c}-p_{s} w p \geqslant 0$ for all $\varepsilon>0$. The additional assumptions along with (11) are assured by the condition that $p_{c} \geq 0$ for all $c \geq 0$. When $\mathbf{T}=0$, in which the cash-in-advance constraint applies only to consumption, then (11) simplifies to $f_{i=} \propto p f_{k}$. This is exactly the same as the Correspondence Principle (CP) discussed in Chen et al. (2008) (Note 12).

Next, we conduct comparative statics (Note 13). First, we examine the effect of the growth rate of money supply $\mu$ on capital $k$ at the steady state. It follows from (10) that:

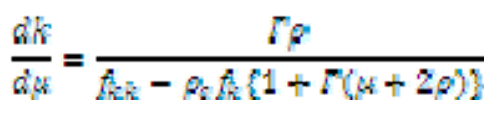

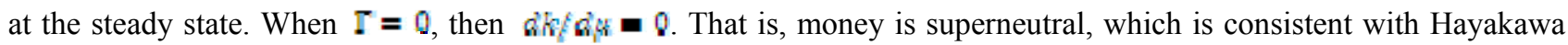

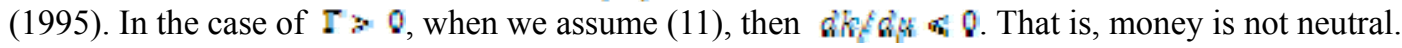

We then investigate the effect of $\mu$ on the other variables: namely, consumption $c$, real balances $m$, and indirect

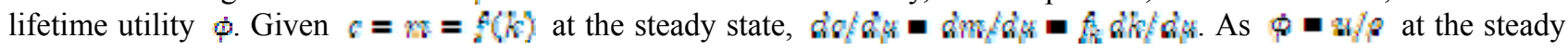
state:

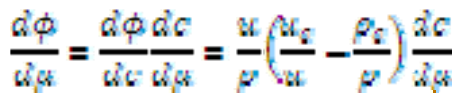

$$
\begin{aligned}
& =(\xi+2) \frac{f_{k}}{\rho} \frac{d k}{d \mu^{\prime}}
\end{aligned}
$$

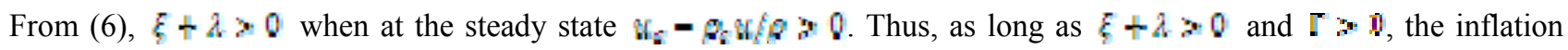
effect on consumption, real balance, and welfare is negative independently of the sign of $p_{s}$.

\section{Discussion}

This section discusses the comparative statics results. First, we explain the mechanism for the comparative statics and discuss the role of the discounting rate function. Then, comparing our results with the extant literature, we establish a qualitative equivalence. Finally, we suggest a future task to further this line of inquiry.

The mechanism of the comparative statics (12) is as follows. From (8), increasing the growth rate of money increases the shadow price ratio of the cash-in-advance constraints to money $A^{\prime \prime} / g^{\prime \prime}$. From (7), increasing $A^{\prime \prime} / g^{\prime \prime}$ affects the shadow price ratio of capital to money $\eta^{2} \xi \xi^{11}$ when $\boldsymbol{T}>0$. Given $f_{k}$ decreases with $k$ and $\theta^{4}-f\left(k^{9}\right)$, equation (9) 
indicates that increasing $\eta^{\prime} \xi \xi$ has a negative effect on the steady-state level of capital. Therefore, as long as the cash-in-advance constraint applies only to consumption, (7) states that the shadow price ratio of capital to money is unaltered, indicating that capital is costlessly obtained through barter (Stockman, 1981). However, when I $\geqslant 0$, higher inflation makes capital more expensive than real balances, and this induces a decrease in the capital stock. The constraint on part or all of investment then operates as a tax on capital goods.

Whether $\rho$ is increasing or decreasing in $c$ (a Tobin effect indicating a positive relationship between inflation and the capital stock) never emerges as long as the CP condition (11) holds. When $\beta=Q$, however, the effect of inflation on the capital stock is mitigated. When $T \geqslant 0$, holding capital is relatively expensive, and inflation lowers the level of consumption along with that of capital. Lower consumption makes economic agents with $\beta_{q} \rightarrow 0$ more patient, thereby moderating the decrease in the capital stock. Conversely, given that agents with $\theta_{\mathrm{s}} \boldsymbol{\theta}$ tend to be more impatient and therefore save less, higher inflation accelerates the decrease in capital stock.

As discussed in the introduction, Wang and Yip (1992) established a qualitative equivalence between the TC, CIA, and MIU approaches using a monetary model with elastic labor supply and constant time preferences. As an alternative, Chen et al. (2008) proved the equivalence between the TC and MIU approaches using a model with inelastic labor decisions and endogenous time preferences. A reverse Tobin effect emerges when the discounting rate is decreasing in real balances in the MIU model and in consumption in the TC model, with such a decreasing discounting rate supported by empirical evidence (Note 14). Using the results in the previous section, we can establish a qualitative equivalence between the TC, CIA, and MIU models with inelastic labor decisions and endogenous time preferences. In our approach, higher inflation lowers steady-state capital, money, consumption, and welfare in the long run when the degree of impatience is decreasing in money in the MIU approach and in consumption in the TC approach, and when money is required not only for consumption purchases but also for part or all of investment in the CIA approach.

As shown in Chen et al. (2008), a Tobin effect emerges when the discounting rate is increasing in consumption and money in the TC and MIU models. In our model, the positive slope of the discounting rate function only moderates the severity of the negative relationship between inflation and capital, and therefore cannot generate a Tobin effect. That is, the effect of the CIA constraint in reducing the capital stock dominates the impatience effect increasing the capital stock. Similarly, if we were to introduce a labor decision in the TC and MIU models, the endogenous labor effect may dominate the impatience effect independently of the slope of the discounting rate. Therefore, exploring qualitative equivalence between the three alternative monetary models with endogenous labor decisions and endogenous time preferences would be an intriguing, albeit complicated, task for the future (Note 15).

Before closing this note, we mention another future task. Our investigation concerns the steady state and we could reasonably extend its dynamic properties around the steady state. As an example, Miyazaki and Utsunomiya (2009) investigated the local stability properties of the TC and MIU models with recursive utility. Regrettably, although Miyazaki (2010) succeeded in characterizing the local dynamics of a generalized CIA model with constant time preferences, the dynamic properties of a generalized CIA model with recursive utility remain unsolved.

\section{References}

Chen, B-L., Hsu, M., \& Lin, C-H. (2008). Inflation and Growth: Impatience and a Qualitative Equivalent. Journal of Money, Credit, and Banking, 40, 1310-1323. http://dx.doi.org/10.1111/j.1538-4616.2008.00159.x

Feenstra, R.C. (1986). Functional Equivalence between Liquidity Costs and the Utility of Money. Journal of Monetary Economics, 65, 271-291. http://dx.doi.org/10.1016/0304-3932(86)90032-2

Hayakawa, H. (1995). The Complete Complementarity of Consumption and Real Balances and the Strong Superneutrality of Money. Economics Letters, 48, 91-97. http://dx.doi.org/10.1016/0165-1765(94)00588-S

Lahiri, R. (2002). The Inflation Tax, Variable Preference, and the Business Cycle. Macroeconomic Dynamics, 6, 496-522. http://dx.doi.org/10.1017/S1365100501010021

Lucas, R.E. Jr. (1980). Equilibrium in a Pure Currency Economy. Economic Inquiry, 18, 203-220. http://dx.doi.org/10.1111/j.1465-7295.1980.tb00570.x

Miyazaki, K., \& Utsunomiya, H. (2009). A Note on Local Stability Conditions for Two Types of Monetary Models with Recursive Utility. Numerical Analysis and Applied Mathematics: International Conference on Numerical Analysis and Applied Mathematics 2009, 2, 953-956. http://dx.doi.org/10.1063/1.3241643

Miyazaki, K. (2010). A Note on Continuous Time Models with General Cash-in-Advance Constraints. Economic Bulletin, 30(4), 2856-2863. 
Miyazaki, K. (2011). Inflation, Growth and Impatience in a Cash-in-Advance Economy. International Advanced Economic Research, 17(4), 488-489. http://dx.doi.org/10.1007/s11294-011-9323-2

Palivos, T., Wang, P., \& Zhang, J. (1993). Velocity of Money in a Modified Cash-in-advance Economy: Theory and Evidence. Journal of Macroeconomics, 15(2), 225-248. http://dx.doi.org/10.1016/0164-0704(93)90026-I

Stockman, A. C. (1981). Anticipated Inflation and the Capital Stock in a Cash-in-Advance Economy. Journal of Monetary Economics, 8, 387-393. http://dx.doi.org/10.1016/0304-3932(81)90018-0

Wang, P., \& Yip, C. K. (1992). Alternative Approaches to Money and Growth. Journal of Money, Credit and Banking, 24, 553-562. http://dx.doi.org/10.2307/1992811

\section{Notes}

Note 1. Specifically, $w(c m)=m[n[c m]$, where $w$ is an instantaneous utility function of money $m$ and consumption $c$, and $m$ and $c$ are perfect complements.

Note 2. Specifically, $T(c, m)=T_{\sigma} I(0<\subset \leqslant m)$ where $T$ represents the transaction cost function, $l$ is an indicator function, and $T_{0}$ is a sufficiently large constant.

Note 3. The conditions are Pareto complementarity between consumption and money, Pareto complementarity between consumption and leisure, and Pareto substitutability between money and leisure.

Note 4. This note is an extended and completed version of Miyazaki (2011).

Note 5. Hayakawa (1995) uses the term 'superneutral' when monetary expansion does not affect any real variable except real balance holdings, and 'strong superneutral' when it also affects real balances.

Note 6. To be exact, the CIA constraint should be binding.

Note 7. For a price level $P_{t}$ at period $t$, the rate of inflation is determined by $\pi_{q}=R_{\mathrm{q}} / \boldsymbol{R}_{\mathrm{q}}$.

Note 8. Another type of constraint is proposed by Palivos et al. (1993). Their continuous version is $\varepsilon+\pi(\pi, \kappa) k \leq n$. In their model, $\mathbb{\Gamma}$ is a function of the inflation rate $\pi$ and a measure of credit looseness $x$.

Note 9. For any initial price level $P_{0}$, real balances $m_{Q}-M_{Q} / R_{2}$. Real balances $m_{z}$ at period $\nabla$ are choice variables.

Note 10. See Chen et al. (2008) for a justification of the inclusion of endogenous time preferences in a monetary model.

Note 11. It follows from (8) that $2^{\circ} \xi \xi^{s} \geqslant 0$.

Note 12. Chen et al. (2008) proved uniqueness only where the discount rate is independent of real balances in the MIU model. Uniqueness for the remaining cases was only shown graphically without rigorous proof.

Note 13. The comparative statics are evaluated at the steady state with the asterisks omitted to ease the burden of notation.

Note 14. See Chen et al. (2008) for a discussion of the empirical literature on endogenous time preferences.

Note 15. Lahiri (2002) conducted a calibration analysis of a cash-in-advance model with an endogenous labor decision. However, the cash-in-advance constraint applied only to the purchase of consumption goods. Calibrating the general cash-in-advance model would be another important future task.

Note 16. We assume capital depreciation is zero to compare our results with those in Wang and Yip (1992) and Chen et al. (2008). However, introducing positive capital depreciation produces the same comparative statics results.

Note 17. An example satisfying the conditions is $\nleftarrow(\delta)=\sigma^{2-\varepsilon} \xi(1-\sigma), \sigma-1$. 


\section{Appendix}

This appendix provides the necessary and sufficient conditions for optimization in which the economic agent maximizes (3) subject to (1) and (2) and the initial and transversality conditions. We denote investment by $x=k$ (Note 16). The present value Hamiltonian is:

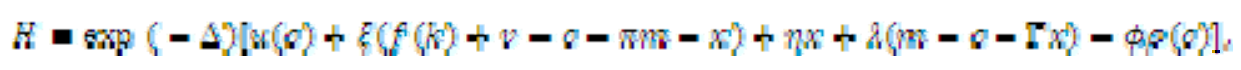

where $\lambda$ is the Lagrange multiplier for the cash-in-advance constraints, and $\xi, \eta$, and $\phi$ are the costate variables for $m, k$, and $\Delta$ respectively. As shown in the next paragraph, $\neq$ is negative when $w<0$. The first-order conditions yield:

$$
\begin{aligned}
& \mathrm{H}_{\mathrm{q}}-\phi \rho_{\mathrm{g}}=\mathrm{B}_{\mathrm{g}}+\mathrm{A} \\
& \eta=\xi+\lambda \\
& \xi=(\theta+\omega) \xi-\lambda \\
& \eta=p-f_{k} \xi \\
& \phi-w \mid \phi \rho
\end{aligned}
$$

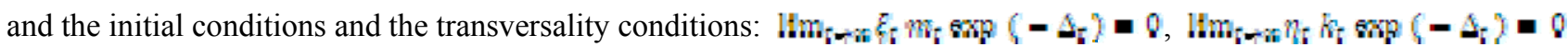

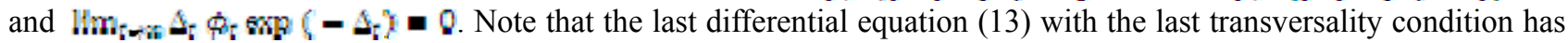
(3) as a solution, leading to $\phi \propto 8$ when $\pi \propto 0$.

For a sufficient condition for the maximization problem, we should assume that the Hamiltonian $H$ is concave with respect to $c, m, \hat{x}, a$, and $\Delta$ for any $\hat{\lambda} \geq 0, \xi \geq 0, \eta \geq 0$, and $\phi \leq 0$, where $\hat{\lambda}=\exp (-\Delta) \lambda, \xi=\exp (-\Delta) \xi$, $\eta=\operatorname{sxp}\{-\Delta) \eta$, and $\phi=\operatorname{se}(-\Delta) \phi$. A sufficient condition for concavity is that $f^{-2} w(Q)$ is concave. Such concavity holds if $u<0, w_{i c}<0$, and $w_{s}-0 ; 0$ for all $c$, excluding the possibility that $s \geqslant 0$. We assume the felicity function satisfies these conditions (Note 17). 